\title{
BUEN VIVIR Y SOCIALISMO INDOAMERICANO una búsqueda epistémico-política
}

\section{Félix Pablo Friggeri}

E-mail: felix.friggeri@unila.edu.br

Universidad Federal de la Integración Latinoamericana (UNILA), Foz do Iguaçu (PR) - Brasil.

DOI: $10.1590 / 3610513 / 2020$

\section{Introducción.}

En el contexto del protagonismo indígena en las luchas populares latinoamericanas enfrentando al neoliberalismo y en el debate sobre los quinientos años de colonialidad en nuestra región, emerge una propuesta ancestralmente vivida por los pueblos y naciones originarias de América que se hizo conocer bajo el nombre de Buen Vivir. Esta propuesta viene demostrando una enorme potencialidad como alternativa política y epistémica en la construcción de un horizonte superador del capitalismo y del eurocentrismo.

Su "Alteridad", dada por la raigambre profundamente popular y originalmente latinoamericana que posee, interpela al mundo académico que experimenta una especie de incertidumbre al querer comprenderla

Artigo recebido em: 08/09/2019

Aprovado em: 12/05/2020 y formularla en los marcos habituales. Pero abre también una fuente de creatividad, originalidad y de reconstrucción descolonizadora de los conocimientos canonizados que se muestra apasionante por su potencialidad, sobre todo cuando va acompañado de una alianza política con los movimientos populares.

Los procesos de los gobiernos latinoamericanos que se presentaron como opuestos al neoliberalismo, entre el fin de un milenio y el comienzo del otro, ayudaron - con mayores o menores ambigüedades - que pudiera debatirse esta propuesta a niveles más amplios. En la búsqueda de alternativas superadoras del neoliberalismo emergió un dilema que podemos expresar como Desarrollo y/o Buen Vivir. Este dilema expresa no solamente un debate sobre el "modelo" a seguir para gobernar a favor de las mayorías populares, sino también sobre el horizonte político que lo determina y los caminos transicionales hacia él.

Pero al presentarse el Buen Vivir como horizonte superador del capitalismo, aparecen las posibilidades 
de confluencias con otras vertientes que históricamente han luchado por ese objetivo en nuestra región. Así surge el problema de su relacionamiento con un Socialismo a construir latinoamericanamente, tal como se evidenció en propuestas de varios de estos gobiernos.

Comienzo este trabajo exponiendo brevemente algunas de las expresiones indígenas en la línea del Buen Vivir y sus elementos comunes. Después, analizo el dilema de su confrontación con el tema del desarrollo en la problemática regional. En un tercer punto, trabajo su relación con planteos latinoamericanos, principalmente con la propuesta mariateguiana del Socialismo Indoamericano. En un cuarto punto, abordo algunos elementos sobre la necesaria reconstrucción epistémica que el tema exige, lo que constituye uno de los aportes más originales y potencialmente más revolucionarios y abarcativos de esta propuesta.

Además de las obras de Mariátegui y de otros trabajos bibliográficos, trabajo con el material de entrevistas realizadas en Ecuador junto a los Movimientos Indígenas. ${ }^{1}$

\section{El Buen Vivir}

Seguidamente presento, en forma breve, diversas expresiones del Buen Vivir en las cosmovisiones indígenas de América Latina y algunos ejes comunes para comprender inicialmente su potencialidad.

La expresión quechua del Sumak Kawsay es una de las más conocidas y fue consagrada como principio constitucional en Ecuador en 2008. Sumak indica no solo un calificativo de bondad sino más claramente de plenitud. Kawsay expresa la actividad vital relacional y compartida, con los otros humanos y con la naturaleza, con una idea comunitaria que abarca ambos ámbitos. Sería entonces "la vida en plenitud" (Macas, 2010, p 25): una construcción colectiva permanente con base ancestral que está centrada en la vida en comunidad, lo cual abarca la comunidad humana y la relación con la Pachamama. ${ }^{2}$ Así configurada, expresa un carácter claramente opuesto a la economía capitalista y a los supuestos culturales que conlleva:
El Sumak Kawsay está llamado a romper la economía hegemónica basada en el lucro, en la explotación del trabajo y de la naturaleza; el Sumak Kawsay cuestiona el capitalismo centralizado acaparador, depredador, egoísta, competitivo y excluyente. El Sumak Kawsay se basa en otra racionalidad, en la armonía entre las personas, entre las sociedades y la naturaleza, y para que haya una armonía necesitamos una economía comunitaria, recíproca, solidaria, con una visión de bienestar material y espiritual desde los pueblos y para los pueblos. (Tenesaca Caguana, 2013, p. 18)

El principio aymara del Suma Qamaña es equiparable, en principio, al anterior. Traducido en Bolivia como "Vivir Bien", los intelectuales indígenas destacan su comparación con el modelo del desarrollo tipificado en el "Vivir Mejor". La gran diferencia es que "en el suma qamaña nunca va a ser mejor si no es con todos" (Yampara Huarachi, 2007, p. 127).

Podemos encontrar equivalencias en el Teko Porã guarani - que explico más abajo -, aunque en esta cosmovisión es más central el Nandereko. Este último es un principio identitario que podría traducirse como "nuestro modo propio de vivir" y que contiene también una fuerte dimensión contrastiva fortalecida, muy posiblemente, en oposición al modo de vivir que impone la colonialidad. El Ñandereko fue consagrado como principio constitucional en Bolivia. Es un modo de ser ancestral, de ymaguare. Como modo de ser propio, y en contraposición a la mala vida que propone la colonialidad, es Teko Porã. En principio podríamos equiparar este último al principio constitucional boliviano del Teko Kavi del guarani de las tierras bajas del sudeste boliviano. Indica, en principio, "vida buena”. Porã, en el guaraní que se habla más al este, es bueno, pero primero indica lo "lindo", como agradable de vivir, como una forma que enamora, que vale la pena profundamente. Como términos cercanos y complementarios están los de teko catu (con una connotación más de afirmación de identidad) y teko marangatu (que denota la bondad unida a lo maravilloso, a lo sagrado, a los atributos éticos de la persona) (Chamorro, 2004, p. 119-120).

Entre los mayas, Antonio Paoli (2001) ha estudiado el Lekil Kujlejal, de los tseltales, unidos a la lucha 
zapatista. Es "la vida buena por antonomasia", forma ancestral, agredida pero viva, que se transforma en guía real y existente de vida: Unido al concepto de slamalil k'inal, traducible, en principio, como "paz" que es el medio ambiente externo conformado por una unidad donde todos influyen y toman la influencia de los otros para formar un solo corazón, un concepto colectivo y cósmico que indica la armonía conjunta e interdependiente de ambos aspectos que repercuten en la persona al estar unida a esa armonía y participar entonces de esa paz. El sentido dinámico de estos conceptos se expresa por la palabra de la asamblea que es la única manera de buscar la vida comunitaria. También en los tojolabales el lekilaltik es entendido en esta línea (Concheiro Bórquez y Núñez, 2014, p. 186).

Hay, así, múltiples expresiones de distintos pueblos, pero podemos encontrar en estos ejes de las cosmovisiones de los pueblos indígenas del Abya Yala una llamativa presencia de elementos comunes que dan pie para un planteo conjunto en lo político y en lo epistémico.

Antes de avanzar, conviene recordar que hay un concepto que expresa el proceso de los Movimientos Indígenas latinoamericanos, transformando este eje vital en una propuesta política más allá de sus comunidades, se trata de la "politización de lo étnico", un concepto que condensa el camino de superación de las dificultades históricas provenientes de la acentuación de algunos aspectos unilaterales de estas luchas.

El concepto de politización de lo étnico, supera, por un lado, la acentuación en lo étnico que valorizaba las diferencias pero que al remarcarlas radicalmente favorecía una atomización política de los distintos pueblos originarios. En sus peores versiones tendía a cierta folcklorización de sus características evitando las referencias a la conflictividad social y política en las que viven. Por otro lado, la acentuación política estuvo muchas veces marcada por una pobreza en la lectura de lo identitario y en la secundarización de aspectos claves de la cultura y la espiritualidad indígena, subrayando casi exclusivamente su ligazón a una concepción de la lucha de clases eurocéntricamente presentada y, muchas veces, invisibilizando lo indígena bajo el acento de su presentación desde el punto de vista de su fuerza de trabajo. Una muestra de esta segunda postura era la tendencia a encubrir lo indígena bajo la denominación de "campesinos", colocando a estos colectivos en subordinación al proletariado urbano y/o minero.

La maduración en la visión que se expresa en el concepto de politización de lo étnico tuvo uno de sus momentos claves en los finales del Siglo XX y comienzos del XXI y dos hechos fueron fundamentales: la contestación al neoliberalismo que se imponía en la región y los preparativos para la "celebración" de los quinientos años de la invasión europea. Los Movimientos Indígenas consiguieron en esos momentos una mayor visibilidad y también aportes logísticos, sobre todo a nivel de los organismos internacionales. Esto contribuyó a fortalecer su organización y articulación en toda América Latina. También ayudó en la construcción de un discurso con denominadores comunes, uno de cuyos frutos es la propuesta del Buen Vivir que, forjada en el mundo andino, referenció también expresiones de otros lugares. En ese proceso surgieron otros conceptos claves, principalmente los de Interculturalidad (que maduró en el trabajo educativo) y el de Plurinacionalidad (cuyo planteo de reestructuración del Estado-Nación es, quizás, uno de los más profundos desde la fundación de estos en la región).

Además de la repercusión en la estructuración estatal y la educación, la politización de lo étnico influyó en otros ámbitos como el económico, el de género y el ecológico. $\mathrm{Al}$ dar una proyección política a la praxis ancestral indígena de lucha por la vida - que incluye tanto las manifestaciones colectivas más visibles como las luchas de la vida cotidiana - ella proporciona un aporte fundamental para la superación de esos peligros de unilatelarización y ayuda a gestar una propuesta política cargada con la riqueza de la praxis cultural que vemos expresada en las propuestas de Buen Vivir. Otra gran virtud que tiene este proceso y su expresión conceptual es que une fuertemente y en interacción dialéctica la praxis política y la producción de conocimiento propio, esto es, lo político y lo epistémico.

Volviendo a los elementos comunes, destacamos algunos: 
1) La centralidad de lo comunitario y de una ética de reciprocidad. Esto abarca tanto un sentido fuertemente igualitario en la convivencia humana como la búsqueda de una armonía con la naturaleza percibida como un alguien lleno de una vida a la cual se pertenece indisolublemente. La visión es claramente opuesta a la capitalista que se basa en la explotación del hombre y de la naturaleza en una relación marcada por un individualismo egoísta y una naturalización de la desigualdad. También evidencia la vitalidad de la continuidad humano / naturaleza, sin la escisión típica del planteo moderno. Este elemento es nuclear para la propuesta política y epistémica.

Desde la visión de las Nacionalidades, lo comunitario está constituido por la comunidad humana y su entorno, o todos los elementos de la comunidad natural. Es decir, la comunidad humana y todas las formas de existencia, aquellos elementos vitales como parte esencial de la Naturaleza. Las Nacionalidades Originarias de estas regiones geográficas y políticas, nos consideramos una partícula que se gesta bajo el abrigo de la Pachamama. (Macas, 2010, p. 17)

2) En continuidad con esto, lo que Gudynas (2011) retoma como "paradigma biocéntrico". El concepto utilizado por la Ecología Profunda y la Ecología Política de raíces eurocéntricas encuentra en el ámbito latinoamericano y especialmente en la sabiduría de la praxis indígena una plenitud de sentido y una riqueza polisémica que me animo a llamar claramente superadora en calidad y fecundidad. Esto es así porque contiene una fuerza inigualable que viene de una praxis ancestral y milenaria, $y$, sobre todo, actualmente viva e inspiradora. Este paradigma se descentraliza y enriquece desde la periferia. Resignificado desde la experiencia indígena latinoamericana, indicaría que toda la gestación del pensamiento que inspira la acción y la construcción del conocimiento está centrada no solamente en el humano, y menos en el humano aislado, sino que se centra en la vida entendida desde una relacionalidad integral propia de las cosmovisiones indígenas. Esta relacionalidad está unida a la indivisibilidad de los seres centrada en la vida por la cual se puede afirmar que toda praxis humana es, de alguna forma, siempre colectiva y cósmica. En este planteo podemos ubicar el establecimiento constitucional en Ecuador de los Derechos de la Pachamama con un carácter original y pionero a nivel mundial en el ámbito jurídico (Acosta, 2010, p. 11) y que instala en el debate científico de todas las "disciplinas" un elemento clave para una revisión epistémica crítica de los presupuestos capitalistas, coloniales y modernos. El gran acierto de la constitución ecuatoriana está en la palabra "o", a mi entender una de las claves interpretativas de todo el texto constitucional. Al hablar de "Derechos de la Naturaleza o Pachamama", posibilita entender que se entiende naturaleza como Pachamama, y no en su sentido occidental. Por esto, la interpretación de este derecho debe ser hecha fundamentalmente por aquellos que entienden qué es la Pachamama: las comunidades indígenas y sus sabios. Esto debería ser tenido en cuenta por la producción intelectual y, especialmente, por los creadores de jurisprudencia. Justamente se entiende que:

(...) dentro de ella se generan las condiciones de armonía y el equilibrio para lograr la plenitud en toda la comunidad ampliada. (...) La vitalidad de todas las existencias constituye la vida y en esta relación vital se constituye la concepción y la práctica del sistema comunitario. (Macas, 2010, p. 21)

Este paso del paradigma antropocéntrico al biocéntrico desde lo indígena constituye un cuestionamiento central para todo el pensamiento moderno, incluso para buena parte del llamado de "izquierda". Es un "pensamiento unificador en torno a la vida" (Sarango Macas, 2009) ya que la vida es el gran elemento totalizante y relacional.

3) La referencialidad a lo ancestral. Relacionado con una concepción de lo espaciotemporal que en principio me animaría a llamar "en espiral": donde el "pasado" nunca lo es totalmente y por eso es capaz de emerger, ya que "tenemos el pasado presente” (Vargas, 2009). Una dinámica que consiste en un "mirar atrás para ir hacia adelante" como expresa el principio aymara del quip nayralquip ñawi (Mamani Condorí, 2007, 
p. 304). Rodolfo Kusch (1978, p. 29) describe la concepción aymara como "un tiempo mítico que parte del presente cotidiano, se realimenta en el pasado y se concreta en un futuro escatológico". Este elemento se relaciona con lo que denominamos "Ancestralidad del Saber" que explico más abajo.

4) Unido a esto, el papel de la memoria. Entendida como "la fuerza interna que les permite reconocer sus capacidades para desarrollar planteamientos $y$ aspiraciones propias" (Naveda Félix, 2007, p. 317), es una memoria colectiva que sustenta el alto grado de autonomía de las luchas y propuestas del Movimiento Indígena (García Linera, 2001). A la vez sustenta y se nutre de las luchas actuales. Implica un trabajo constante de reconstrucción entendido como un proceso dialogal e intergeneracional que viene unido a la reconstitución política de las comunidades $y$, por eso, al proceso de politización de lo étnico.

5) El valor de la asamblea: "es una reverencia misma a la vida" (Pucha, 2009); "es el poder real que está en el pueblo, en la base, cuando toma decisión una asamblea comunal, ... es fundamental, eso se respeta, porque ahi se planifica, abíse discute, se analiza y a esa asamblea se somete" (Cholango, 2009).

6) La vinculación de la espiritualidad con todos los aspectos de la vida, incluída, fuertemente, la praxis política (Churuchumbi, 2014, p. 39).

7) La conexión entre la vida cotidiana y sus criterios con la praxis económica y política. Inscribiéndose en un proceso histórico de organización social de los pueblos indígenas, con carácter de vivencia, de experiencia milenaria (Macas, 2010, p. 32).

Este conjunto de elementos comunes habilitaría la posibilidad de hablar de una propuesta panétnica en el discurso político indígena en América Latina. Manteniendo la conciencia de la diversidad de los pueblos y naciones indígenas, esto es importante a la hora de la construcción de una propuesta conjunta a nivel político y también a nivel epistémico. Resumiendo, ellos muestran una búsqueda que es, a la vez, espiritual y política, hacia una vida plena. Que se hace en las raíces de los pueblos indígenas generando una autonomía, autenticidad y originalidad de pensamiento que América Latina se debe a sí misma. Pensando en un sentido comunitario y revolucionario de la economía y teniendo como referenciales fundamentales la comunión entre los humanos y la indivisibilidad humanos / naturaleza. Aunque se ha consagrado el uso del Buen Vivir principalmente en Ecuador - y del Vivir Bien - en Bolivia - con todo lo visto quizás pueda expresarse más bien como "Convivir plenamente" abarcando la comunidad humana y la de toda la naturaleza, entendida desde las cosmovisiones originarias.

Esta praxis de vida indígena expresada en el Buen Vivir es ofrecida desde el mundo indígena como alternativa a toda la humanidad: “(..) un aporte, que puede constituirse en un elemento fundamental para el cambio histórico" (Macas, 2005, p. 37). Su recepción desborda lo regional. Varias izquierdas europeas (Podemos en España, Jean-Luc Mélenchon en Francia, Jeremy Corbyn en Inglaterra) le han dado a estas visiones una fuerza inspiradora buscando una oposición más nítida y alternativas originales al atropello del capitalismo salvaje.

\section{El dilema Desarrollo y/o Buen Vivir y los gobiernos populares en América Latina.}

La emergencia de una serie de gobiernos latinoamericanos que se presentaron como oposición al neoliberalismo entre fines del siglo pasado y comienzos del actual produjo la configuración de un dilema sobre el modelo económico-social a implementar. Lo describimos como Desarrollo y/o Buen Vivir. La actual derechización parcial de la región plantea un neoliberalismo que nunca podrá ser defendido desde una postura solidaria con las mayorías populares, y, a la vez, profundiza y acentúa la vigencia de este dilema porque obliga más urgentemente a encarar las dificultades que ambas propuestas traen. En los dos países donde se expresa con más fuerza - como Bolivia y Ecuador - los movimientos políticos que originaron estos procesos se sostuvieron un buen tiempo en el poder. Además, después del que podríamos llamar el período más duradero y amplio de democratización en la región, es necesaria una evaluación y un replanteo de las políticas implementadas, ya sea por haber perdido ese poder - vía golpes institucionalizados o 
en elecciones formalmente democráticas - o porque necesitan fortalecer sus propuestas frente al embate de la derecha neoliberal.

Se puede afirmar que el planteo predominante de estos gobiernos estuvo más ligado a la idea del desarrollo, aunque hubo una apertura de distintas magnitudes y formas a la propuesta del Buen Vivir. Para las dirigencias predominantes del mundo económico y político el planteo desarrollista aparecía como más conocido y aceptable dentro de la estructuración económica y las correlaciones de fuerza vigentes. En este hecho fue importante que los productos primarios que son objeto de una dinámica extractivista (tanto en lo agropecuario como en lo minero) gozaron de precios relativamente buenos con respecto a otras épocas (Gudynas, 2017, p. 112), lo cual daba la posibilidad de transferir excedente a la inversión social y hacia un relativo proceso de industrialización por sustitución de importaciones. Esto posibilitó procesos de redistribución del ingreso - no así de la riqueza (Acosta, 2016, p. 27) - relativamente rápidos y la formación de un consenso social mayoritario.

Por otro lado, una legislación y una política pública que viabilice el fortalecimiento y la extensión de una economía orientada hacia el Buen Vivir requieren de una valentía y creatividad difícil de encontrar entre el personal político y de sostener frente al aparato oligárquico jurídico, mediático y legislativo. Esto es evidente aún en los países que lograron dar una base constitucional fuertemente habilitante para ello.

Existe una contradicción teórica excluyente entre ambos conceptos (Macas, 2010, p. 35-36; Acosta, 2010 , p. 9) que ubica en campos opuestos a cualquier planteo de "Desarrollo" - hasta el que encontremos como más humano, social o con pretensiones ecológicas - frente al Buen Vivir. Este último no podría nunca ser contado como una de las propuestas de "desarrollo alternativo" porque cuestiona "toda la base conceptual del desarrollo occidental' (Gudynas, 2010, p. 43). El núcleo de esta oposición está en la pertenencia de todo planteo desarrollista - más central o marginalmenteal sistema capitalista. Aunque los gobiernos populares de la región plantearon una retórica de superación del neoliberalismo - acompañada muchas veces de políticas concretas, aunque parciales - no puede afirmarse con claridad y certeza que establecieron un curso de superación del capitalismo.

La potencialidad del Buen Vivir como alternativa y superación del capitalismo no vale solo para el terreno económico, sino que aporta a un "debate civilizatorio" (Santos, 2010, p. 5), ya que frente a lo que se entiende como crisis del mundo occidental y capitalista (García Linera, 2017) los movimientos indígenas de América Latina ofrecen al Buen Vivir como una potente y fecunda alternativa para toda la humanidad, sobre todo para los pueblos del Sur político.

Para el análisis de este dilema, entiendo importante recuperar el planteo de la llamada Heterogeneidad Estructural de nuestra región que fue uno de los elementos claves del análisis de la Comisión Económica para América Latina (CEPAL). Hay elementos de este debate que queremos replantear desde la mirada de José Carlos Mariátegui. Ya en el planteo del llamado dualismo latinoamericano, más propio de las Teorías de la Modernización y de las del Desarrollo externas al análisis de la Cepal, aparecía fuertemente una "parte" de América Latina catalogada como atrasada, arcaica, estancada, retrógrada, basada en relaciones personales y familiares, en el trabajo colectivo (Stavenhagen, 1970, p. 174) y que había que necesariamente superar estas características porque se identificaban con el subdesarrollo. La mirada era de una negatividad absoluta frente a este "sector" de América Latina: valía solamente extinguirlo y lo más rápidamente posible si se quería avanzar por el camino de la Modernización y el Desarrollo. En ese sector ubicaban siempre a indígenas y campesinos. Eran un "mundo" a ser superado, cuya mayor negatividad era impedir o molestar el crecimiento ordenado y pujante del otro "mundo" más claramente encuadrado en el capitalismo.

El trabajo analítico de la Cepal intentó complejizar aquel planteo y distinguirse del dualismo. Fue una de las funciones que cumplió el concepto de heterogeneidad estructural que tuvo elementos interesantes pero también dificultades: siguió alineado a la matriz evolucionista eurocéntrica y ligado a una visión principalmente negativa de la parte "no capitalista" de América Latina (Acosta, 2014, p. 25). Además, 
su base epistémica no alcanzaba para configurar un pensamiento desde América Latina.

Aníbal Quijano (2014, p. 288) entiende que el embrión del concepto de "heterogeneidad históricoestructural" está ya en Mariátegui y que es un elemento clave frente al dualismo eurocéntrico y evolucionista. Pero entiendo que lo más importante es que el Amauta sabe encontrar la positividad y potencialidad alternativa y revolucionaria que poseía aquella "parte" que era juzgada solo negativamente. Allí donde se veía la dificultad estaba precisamente la alternativa superadora. Era algo que no veían ni las derechas procapitalistas, ni buena parte de la izquierda, ambas colonizadas y - en distintos sentidos - colonizadoras.

Aquí me parece enriquecedor sumar el concepto de exterioridad de Enrique Dussel, quien sostiene que el pueblo "en tanto oprimido es 'parte' del sistema, es clase social o 'bloque' explotado (...) con su trabajo (...) permiten vivir a los 'ricos' (...)" (Dussel, 1987, p. 95). Pero, a la vez, es portador de una "positiva exterioridad cultural" y esto lo hace lugar político y epistémico de gestación de la creatividad necesaria para construir el camino de liberación (Dussel, 1977, p. 69). Dentro de este pueblo la más clara "positiva exterioridad cultural" al sistema dominante se hace realidad en el mundo indígena lo cual se expresa en sus movimientos políticos e intelectuales.

Tomando este aporte de Mariátegui, podemos animarnos a decir que el Buen Vivir está expresando básicamente esa misma idea. Desde la periferia de la periferia (Tortosa, 2011, p. 13) emerge una alternativa superadora del capitalismo y el sujeto político y epistémico de esta propuesta invita a reformular quién es el sujeto revolucionario en América Latina, quién sería ese "proletariado" latinoamericano que inspira la lucha popular y superadora del capitalismo. Lo que podríamos llamar la "ventaja" del Buen Vivir como horizonte superador del capitalismo está relacionado a que es una propuesta construida desde nuestra región y de que no se trata solamente de una idea teórica o una utopía por realizar, sino que es una realidad existente que tiene siglos de construcción dinámica y de vida persistente y que, aún con muchas heridas a lo largo de la historia, está vigente en numerosas comunidades indígenas y campesinas, principalmente.
Otra ventaja es su capacidad abarcativa: impacta tanto en lo político, como en lo económico, epistémico, ecológico y espiritual. Esto proviene de su origen cosmovisional que lo aleja de cualquier tipo de compartimentación tanto en la construcción del saber como en la de la praxis.

El origen popular de la propuesta puede, además, potenciar una referencialidad constante en las mayorías pobres del continente tanto en la gestación, la interpretación y la concreción de la misma. Esto abre caminos participativos, de consulta, de diálogo de saberes, de interculturalidad que reditúan en una democratización política y social. Potencia en forma práctica la interacción de los movimientos populares con otros sectores políticos que se pudieran convencer y aliar a esta propuesta.

Pero también es cierto que la propuesta del Buen Vivir tiene dificultades para una implementación más general, y, sobre todo, más inmediata en muchos aspectos. Entiendo que esto no tendría que convertirse en una inviabilización de la propuesta, sino en una invitación a la reflexión y a la creatividad afianzada en el valor de sus presupuestos.

Una de ellas tiene que ver con la base comunitaria necesaria para su efectivización. La occidentalización individualizante que afecta a toda la población, principalmente a los sectores medios y altos, trae aparejado un desafío para su comprensión, aceptación y puesta en práctica. Los procesos de descampesinización y urbanización que afectaron y afectan los ámbitos populares especialmente a los más jóvenes; una educación que sigue bajo criterios moderno-occidentalistas llevando a cabo una tarea etnocida; pero, sobre todo, la profunda penetración de los criterios mercantilizantes de los "medios de comunicación" concentrados, imponiendo imaginarios de los sectores dominantes como los verdaderos "educadores" de estos tiempos. Aquella cultura comunitaria - fundamentalmente indígena y campesina - que fuera fundante de las periferias urbanas populares se encuentra hoy "lastimada" porque generación a generación han recibido el embate "desconcientizador" de la dinámica globalizante de las ciudades (Acosta, 2014, p. 37) y, hace ya unas décadas, de la importante presencia del "trabajo sucio" del narcotráfico. Todo esto complejiza el panorama 
y merece ser tenido en cuenta seriamente, aunque, entiendo, no lo inviabiliza.

Hay que tener en cuenta la reafirmación de un trípode de poder integrado fundamentalmente por tres sectores: el mediático, el judicial y el empresarial agrario / minero / financiero, valiéndose de todos sus potentes recursos y, sobre todo en los gobiernos derechistas de las fuerzas públicas armadas y de otros agentes violentos paraestatales. La articulación de estos tres factores de poder ha demostrado una inmensa capacidad de desprestigiar, frenar y reprimir las iniciativas y la movilización popular por justicia e igualdad y de condicionar y/o bloquear las medidas gubernamentales que respondan concretamente a las mayorías populares. También afecta cualquier tipo de creatividad alternativa tanto institucional como extrainstitucional. La "lejanía” desde la que actúan, evitando el contacto directo con la mayoría de la población, les da una apariencia de inaccesibilidad y oscurecen la evidencia de sus responsabilidades.

También se requiere un profundo y constante análisis crítico de las experiencias que han invocado el Buen Vivir como política de gobierno. El caso ecuatoriano quedó más alejado de las ideas claramente indígenas, entre otros factores por el evidente enfrentamiento de Correa con la dirigencia de los movimientos históricos (Lalander y Ospina Peralta, 2012; Altmann, 2016, p. 71). En el caso boliviano existe un debate muy rico que conviene seguir, porque aparecen elementos muy valiosos junto a otros que son objeto de crítica, entre ellos tendencias clientelistas y verticalistas (Escárzaga Nicté, 2017). Uno de los grandes interrogantes es la relación de estos gobiernos con las "burguesías". De Correa se critica, especialmente, la alianza con sectores contratistas del Estado y especialmente con el empresariado extractivista. En Bolivia se puso en cuestión, entre otros casos, el surgimiento de una "pequeña-burguesía indígena" tanto urbana como rural, junto a distintas alianzas como con sectores del agronegocio cruceño y de la burguesía brasilera. Estas contradicciones se pusieron de manifiesto con gran claridad con ocasión del golpe de estado perpetrado en diciembre de 2019. Un caso indicado como emblemático es el del empresario Erwin Saavedra quien era presentado como cercano a García Linera y que, sin embargo, aparece como un informante de la Central de Inteligencia Americana (CIA) (Cruvinel,
2020). Existieron también, en tiempos de inicio de la campaña electoral, diálogos con los representantes del agronegocio cruceño que pretendían negociar la liberación de exportaciones y del uso de agrotóxicos y la oportunidad de participar en una posible alianza público-privada en grandes negocios como el de Puerto Busch proyectado como salida al Atlántico. El análisis sobre si la correlación de fuerzas daba para otro tipo de política excede este artículo, pero es cierto que se intentaron acercamientos, por lo menos parciales, con sectores de la burguesía. De todas formas, en general y en ambos casos, este empresariado "aliado" cuando tuvo la oportunidad de oponerse a estos proyectos ante la posibilidad de eliminarlos del poder, lo hizo activamente.

Entendemos que si se construye un compromiso político de hacer de la propuesta del Buen Vivir un horizonte superador del capitalismo, es tan importante clarificar los componentes de este horizonte como los caminos que deben recorrerse hasta él. Estos caminos necesariamente plurales deben ser objeto de una reflexión profunda en diálogo con la praxis política. Una de las perspectivas que aparece - especialmente en Bolivia - es pensar en la convivencia - por lo menos coyuntural y provisoria - del mejor modelo de desarrollo autónomo posible con el grado máximo posible de componentes sociales y ecológicos con "espacios de Buen Vivir" legitimados, potenciados y articulados lo más posible. Esto unido a una dinámica de transferencia creciente del peso económico, de la amplitud de espacios y del peso político, desde esa economía desarrollista a esa economía comunitaria del Buen Vivir. Esta y otro tipos de ideas necesitan de crítica, reflexión y gestación creativa de propuestas realistas y, a la vez, que no pierdan de vista ese horizonte alternativo y revolucionario.

\section{El Buen Vivir y el Socialismo Indoamericano.}

Sin pretensión de exhaustividad, podríamos exponer tres razones para la necesidad de una confluencia entre el Buen Vivir y las propuestas de las vertientes latinoamericanas revolucionarias.

Primero. Al ofrecerse al Buen Vivir como propuesta civilizatoria para todo el planeta, desbordando el ámbito indígena, necesariamente hay que entrar en 
diálogo, por lo menos, con las otras propuestas que se presentan con la intención de superar el capitalismo. Hace unos ańos, cuando preguntaba a los dirigentes indígenas ecuatorianos quiénes podían ser los aliados en sus luchas y propuestas, el entonces presidente de la central andina Ecuador Runakunapak Rikcharimuy (Ecuarunari) me decía que había que buscarlos "en el campo popular ... las grandes periferias de las ciudades ... el movimiento estudiantil... los sindicatos y trabajadores ... los intelectuales progresistas, de izquierda" (Cholango, 2009) y una comunicadora popular indígena me decía que son "los que realmente saben construir desde las bases" (Chela, 2009).

Segundo. Generalizando podría decirse analiticamente - que hay dos grandes caminos que fue tomando la lucha política indígena: la búsqueda de la autonomía y la reestructuración descolonizadora del Estado-Nación. En la realidad siempre se entrecruzaron, algunas veces más expresamente. Sobre todo cuando se prioriza el segundo este diálogo con otras vertientes anticapitalistas se hace evidentemente más necesario.

Tercero. Un cuestionamiento para el Buen Vivir es sobre su proyección política y su capacidad de oponerse al capitalismo y de constituir una alternativa superadora del mismo. Una política de alianzas con los movimientos que plantean esto mismo ayudaría a clarificar una respuesta a este cuestionamiento.

Esta confluencia implica un diálogo de los saberes forjados en las luchas populares latinoamericanas que también se han presentado y se presentan, con la pretensión de superación del capitalismo, como vertientes revolucionarias (marxistas, anarquistas, del cristianismo de liberación, de los populismos de izquierda, del nacionalismo antiimperialista, etc.). Sobre todo buscando lo que podemos llamar un socialismo propio latinoamericano.

Aquí los planteos del Buen Vivir tienen mucho que aportar a una relectura descolonizadora de estas vertientes enriqueciéndolas y ayudándolas en su búsqueda de enraizamiento popular y concreción revolucionaria. Los puede ayudar a liberarse de elementos eurocéntricos opresores vinculados a lo moderno / occidental / colonial. Un aporte clave es poder entender el planteo revolucionario con un doble componente inescindible político y epistémico, que deberá estar presente en ese diálogo de saberes.
Uno de estos diálogos necesarios, y con enorme potencialidad, es con el marxismo. Y aquí, nuevamente, entiendo oportuno recurrir a Mariátegui. Hay una serie de autores que han venido trabajando esto con profundidad: Alberto Flores Galindo, Aníbal Quijano, Álvaro García Linera, por mencionar solamente algunos. La recuperación del "Marx tardío", especialmente en su relación con el populismo ruso, es una de las líneas más fecundas en este sentido. Allí aparece la posibilidad de pensar un camino al socialismo desde las comunidades campesinas, incluso sin tener que pasar por el capitalismo, entendido esto como "la mejor oportunidad que jamás la historia haya ofrecido a un pueblo"(Marx, 1990, p. 172).

Esta revisión del marxismo desde lo indígena puede ayudarlo a encontrar más claramente un enraizamiento profundo en la realidad latinoamericana y en hacer crecer su potencialidad revolucionaria desde la praxis de nuestros pueblos.

Nuestra primera y gran inspiración en este punto es la propuesta del Socialismo Indoamericano de José Carlos Mariátegui. Entiendo que vale volver al texto símbolo de esta propuesta:

No queremos, ciertamente, que el socialismo sea en América calco y copia. Debe ser creación heroica. Tenemos que dar vida, con nuestra propia realidad, en nuestro propio lenguaje, al socialismo indoamericano. He aquí una misión digna de una generación nueva. (Mariátegui, 2005, p. 452)

Sin pretender un análisis exhaustivo de la propuesta de Mariátegui, puntualizo algunos elementos de encuentro con el Buen Vivir que entiendo claves.

El primero es entender a lo indígena como "punto de partida” del camino al socialismo en América Latina (Lowy, 2008, p. 4). No puede haber socialismo "si no se solidarizarse, primeramente, con las reivindicaciones indigenas" (Mariátegui, 2005, p. 378), ya que la "fuente principal de energía revolucionaria" está en lo indígena (Flores Galindo, 2008, T.V, p. 262).

Esto implica una redefinición del sujeto revolucionario, del "proletariado", en América Latina. Como sujeto político y como sujeto epistémico. Mariátegui convirtió en "problema" y en "búsqueda" aquello que 
era una certeza en buena parte de la izquierda: cómo está compuesto este sujeto revolucionario (Flores Galindo, 2008, T. V, p. 371). Lo indígena operará como elemento central en esta búsqueda.

El otro gran elemento central es la necesidad de la articulación de todos las sectores y tendencias revolucionarias desde la praxis de lucha popular. Esta articulación que tiene su base en la alianza obrera / indígena determina la importancia central que tienen para él los sindicatos y los ayllus (Germaná, 1995, p. 155-157). Es "la forma históricamente particular" que, para Mariátegui, tiene "la consigna leninista" de esta alianza y tiene como nota fundamental la determinación autónoma de estas organizaciones para su fortalecimiento (Aricó, 2017, p. 315-316), apuntando a un partido concebido como "movimiento de masas" (Flores Galindo, 2008, T. V, p. 367; Germaná, 1995, p. 158-159). ${ }^{3}$ Esta afirmación de la autodeterminación implica la negación de pensar a la "burguesía nacional" como un aliado deseable y confiable dada su sumisión al capitalismo monopólico internacional y, por tanto, al imperialismo (Quijano, 2014, p. 408). Las "burguesías nacionales", desde un imaginario plenamente racista tenían, frente a la población indígena y negra, "el mismo desprecio que los imperialistas blancos", por eso son "instrumentos dóciles del imperialismo yanqui o británico”, esto inviabilizaba cualquier tipo de alianza que pueda plantear en común una "lucha por la independencia nacional" ya que "entre el señor o el burgués criollo y sus peones de color, no hay nada en común" y es "el concurso de las burguesías nacionales" el que le permite a este imperialismo un crecimiento en sus ganancias al concretar una explotación extrema (Mariátegui, 2017, p. 66). Por eso considera como una seria equivocación, en una comparación hecha especialmente con la experiencia en China, el tener expectativas de una postura revolucionaria y antiimperialista en estos sectores:

Pretender que en esta capa social prenda un sentimiento de nacionalismo revolucionario, parecido al que en condiciones distintas representa un factor de la lucha antiimperialista en los países semicoloniales avasallados por el imperialismo en los últimos decenios en Asia, sería un grave error. (Mariátegui, 2010b, p. 118)

Por todo esto, el primer concepto presente en el Acta de Constitución del Partido Socialista Peruano es que esta alianza obrero-campesina "netamente clasista" es "base de la lucha contra el imperialismo extranjero y la burguesía nacional" (Mariátegui, 2010b, p. 400).

Destaco, también que en cuanto "creación heroica" este socialismo es una construcción desde la praxis revolucionaria. Se entiende solamente desde el interior de la lucha de clases - a la cual incorpora fuertemente la problemática "étnica" y "nacional" -, pero se comprueba su veracidad por su capacidad de alentar a las multitudes, de encarnarse con ellas (Flores Galindo, 2008, T. V. p. 357-358.392). Existen en el mundo indígena "elementos de socialismo práctico" que son un "factor ... fundamental" (Mariátegui, 2000, p. 41) y que se convierten en "eventual sustento" de cualquier construcción socialista (Flores Galindo, 2008, T. V, p. 361). Uno de los autores que centra el análisis de la propuesta mariateguiana en este concepto de "elementos de socialismo práctico" nos da una definición del mismo que sería, también, plenamente aplicable al principio cosmovisional del Buen Vivir. Esta definición dice así:

(...) designa la realidad actuante de la comunidad campesina-indígena y de sus históricos lazos sociales, sus hábitos de cooperación y sus modos de relacionarse los seres humanos entre sí y con la naturaleza (componentes societarios y relaciones radicalmente nuevas de intercambio metabólico en la sociedad y de la sociedad con la naturaleza). (Mazzeo, 2009, p. 64-65)

Se trata entonces de la valorización revolucionaria de la praxis comunitaria ancestral de lucha por la vida ejercida durante miles de ańos por los pueblos indígenas $y$, aunque cercada y lastimada, profundamente viva y existente. No se trata de la recuperación de un pasado, se trata de la valorización de un presente pleno de ancestralidad y lleno de dinamismo, tanto político como epistémico. Esta valorización se da en el contexto de la serie de rebeliones indígenas recientes y contemporáneas a la vida del Amauta. Para Mariátegui 
"el socialismo ... está en la tradición americana ... la más avanzada organización comunista, primitiva que registra la historia, es la inkaika"(Mariátegui, 2010b, p. 271). Junto a esto, afirma que es una tradición viva y dinámica: "lo que asegura" la "emancipación" indígena "es el dinamismo de una economía y una cultura que portan en su entrańa el germen del socialismo" y, que por esto hace posible la "creación de una nueva cultura americana" (Mariátegui, 2010b, p. 69-70). Así propone una reivindicación revolucionaria de la tradición indígena, contraria a la reivindicación conservadora y elitista que quiere verla como "inmóvil y acabada", al contrario esta praxis ancestral transmitida "está siempre en crecimiento bajo nuestros ojos" (Mariátegui, 2010b, pp. 343-345), por esto un análisis que se pretenda marxista o la "ve" y la valoriza en su vitalidad y dinamismo, o termina traicionando a sí mismo.

Otro elemento clave tiene que ver con toda la dimensión subjetiva, ética, espiritual que contienen ambas propuestas. Como "creación" implica la negación al calco y la copia eurocéntrica, implica el uso de la intuición y de la imaginación creadora. ${ }^{4}$ Con esto Mariátegui intenta superar cierto racionalismo moderno de las propuestas de izquierda preponderantes. Él subraya esta "heroicidad" desde el concepto de "agonía" - que tan bien destaca Alberto Flores Galindo -, un concepto tomado de Miguel de Unamuno (Mariátegui, 2005, p. 332) y aplicado a la lucha por la vida. Este encuentro de lo espiritual, lo ético y lo subjetivo con el camino revolucionario tiene una de sus expresiones más directas en su concepto de "Alma matinal" al que podemos emparentar con la idea de "Hombre Nuevo" que defendiera el Che Guevara. ${ }^{5}$ Uno de sus instrumentos clave tanto para pensar como para concretar la creatividad y la heroicidad es su planteo del papel revolucionario del mito - inspirado en George Sorel - que tiene que ver con la calidad autodeterminativa del proceso hacia el socialismo pues es el mismo movimiento indígena el que debe encontrar su propio elemento movilizador, su "pasión colectiva”. Es que para él "[...] el socialismo existía y se desarrollaba únicamente en el interior del movimiento de masas" (Flores Galindo, 2008, T. VI, p. 27).
También hay que tener en cuenta que, tanto en la praxis política como en la reflexión epistémica de Mariátegui y en la de los Movimientos Indígenas en nuestra región, tienen siempre presente un horizonte latinoamericano y también una convicción descolonizadora y antiimperialista que los liga a lo que hoy denominamos Sur Político. La unión latinoamericana solamente podía darse en forma contrahegemónica y que la postura antiimperialista tenía que concordar con la creación socialista:

Latinoamérica (...) no encontrará su unidad en el orden burgués. Este orden nos divide, forzosamente en pequeños nacionalismos. Los únicos que trabajamos por la comunidad de estos pueblos somos, en verdad, los socialistas, los revolucionarios. (...) A Norteamérica sajona le toca coronar y cerrar la civilización capitalista. El porvenir de la América Latina es socialista. (Mariátegui, 2005, p. 464)

Puede verse aqui como el núcleo del antiimperialismo en Mariátegui es el anticapitalismo, para él "constituían un mismo fenómeno" (Germaná, 1995, p. 87). Entendía así al imperialismo desde "el carácter de clase" como internacionalización del capital monopólico (Quijano, 2014, p. 406). Junto a esto relaciona al avance capitalista / imperialista la acentuación del carácter de "países semi-coloniales" que se registra en la región (Mariátegui, 2010b, p. 117). Además, relacionaba a los otros pueblos del Sur a su valoración de la potencialidad revolucionaria del Mito (Mariátegui, 2010a, p. 55).

Retomando el tema del sujeto político de este socialismo indoamericano, entiendo que puede expresarse el proyecto de Mariátegui en torno a la formación de un sujeto articulado que tiene su base en esa alianza obrero-campesina y su expresión en la estrategia frentista que plantea. Esta estrategia era una forma de concebir la lucha socialista (Germaná, 1995, p. 160) y el Amauta la expresaba remarcando la necesidad de su amplitud: quería que estén en él los comunistas, pero junto a los socialistas reformistas, los libertarios, los sindicalistas (Mariátegui, 2010b, p. 142). Insistía fuertemente en evitar la fragmentación de la lucha popular cuidando de no "perderse en 
divagaciones teoréticas" o en "estériles debates principistas" ya que "la organización sindical no necesita de etiquetas sino de espíritu" (Mariátegui, 2010b, p. 141). Esta alianza fundamental coloca a la praxis popular de lucha por la vida en el centro de la articulación frentista. Es una articulación basada en la praxis de lucha concreta:

No hay, pues, dificultad efectiva para entenderse acerca del programa de la organización obrera. Están de más todas las discusiones bizantinas sobre metas remotas. El proletariado de vanguardia tiene, bajo los ojos, cuestiones concretas: la organización nacional de la clase trabajadora, la solidaridad con las reivindicaciones de los indígenas, la defensa y el fomento de las instituciones de cultura popular, la cooperación con los braceros y yanaconas de las haciendas, el desarrollo de la prensa obrera, etc., etc. Éstas son las cuestiones que deben preocuparnos capitalmente. Los que provocan escisiones y disidencias, en el nombre de principios abstractos, sin aportar nada al estudio y a la solución de estos problemas concretos, traicionan consciente o inconscientemente la causa proletaria. (Mariátegui, 2010b, p. 142)

En este sujeto se da la controversia por el papel de las burguesías en él, frente a la cual Mariátegui sostiene, como ya fue expresado, que no tiene expectativas concretas.

Una de las grandes discusiones está en el camino a recorrer. En general, hay una coincidencia sobre que la superación del capitalismo no puede hacerse mágicamente de un día para el otro. Algunos entienden que en esa búsqueda habrá que arrastrar, en un inicio, "muchas de sus taras" en "un camino largo y tortuoso, con avances y retrocesos, cuya duración y solidez dependerá de la acción politica para asumir el reto" (Acosta, 2014, p. 28).

\section{La revolución epistémica.}

Luis Macas (2005) había planteado ya hace un buen tiempo que la reconstrucción política propuesta por el Movimiento Indígena en América Latina requería también una reconstrucción epistémica. Muy cercanamente a esto se planteó la "descolonización del saber”. La búsqueda del Buen Vivir adquiere todo su valor y la posibilidad de ser concreta y real si esto es acompañado por una "subversión epistémica" que sea una respuesta popular a la propia realidad latinoamericana desde un pensamiento autónomo, creativo y original.

Esta búsqueda latinoamericana de la originalidad necesita estar referenciada nuclearmente en lo indígena. Como original tiene el doble sentido de ser creativa y enraizada. En cuanto creativa, y aplicando a lo epistémico lo que Mariátegui (2005, p. 452) decía para la construcción del socialismo, el pensamiento latinoamericano no puede ser "calco, ni copia", tiene que ser "creación heroica". En cuanto enraizada implica estar ligada a las luchas populares por la vida - desde las de las organizaciones políticas hasta las cotidianas al interior de cada comunidad - y especialmente a la de los pueblos originarios.

Desde el concepto de politización de lo étnico, que uso como referente para este análisis, pueden plantearse varios aspectos que conviene destacar.

1) La negación de la pretensión de neutralidad científica que es utilizada generalmente para intentar legitimar el principal componente de la Colonialidad del Saber: la pretensión de universalidad del discurso eurocéntrico dominante. Esto es un aporte descolonizador que discute las bases del discurso científico preponderante.

2) Que su potencialidad tiende a desembocar en un sentido de compromiso transformador / revolucionario a la que tendría que caminar la actividad de una construcción latinoamericana del conocimiento.

3) Que se busca encarar situadamente la estructuración conflictiva de nuestra región, en lo que propongo denominar como racismo de clase, el cual caracteriza la dominación capitalista / colonial que padecemos históricamente y en la actualidad. Que se configura en América Latina pero cuyas características se han ido expandiendo a otras regiones.

4) La apertura a la posibilidad de considerar a la sabiduría y a la praxis indígena como fuente clave para una postura epistémica alternativa con 
características revolucionarias. Esto en la línea de lo expuesto sobre el planteo de Dussel de la positividad de la exterioridad cultural que es la base para que, especialmente el mundo académico, se coloque en una actitud de "discipulado" frente a los saberes populares.

5) Frente a la tendencia de encierro disciplinario y a la microespecialización que domina buena parte del trabajo científico regional es importante afirmar el carácter sapiencial del conocimiento relacionado a la mirada cosmovisional que permea todo el pensamiento indígena. Este carácter contiene una interesante dialéctica que relaciona una mirada siempre abarcativa que conlleva una "visión del mundo" que coherentiza toda construcción epistémica desde opciones éticas de vida gestadas comunitariamente y una concreticidad constituyente por estar constantemente referida a la praxis ancestral y cotidiana de crianza y cuidado de la vida siempre comunitaria y cósmicamente entendida.

6) Justamente, que este conocimiento que tiene raíces ancestrales está, a su vez, dotado de una dinamicidad que viene del constante esfuerzo por responder continua y cotidianamente a los desafíos de la lucha concreta. A esto propongo denominar "Ancestralidad del Saber" que ubica la valorización y legitimación del saber en la experiencia milenaria de convivencia y de praxis de lucha por la vida reflexionada comunitariamente, arraigada en la vida comunitaria - que implica tanto la comunidad humana como la comunidad con la "naturaleza" entendida como Pachamama - y que es transmitido como herencia en cuanto saber dinámico, historizado donde son posibles brotes nuevos pero cuya fecundidad está relacionada a la comunicación con la raíz. Este concepto ayuda no sólo a validar los conocimientos indígenas, sino los de grandes sectores populares latinoamericanos. Tiene la capacidad de cuestionar el modelo evolucionista del conocimiento y su modelo de comprensión de la espacio-temporalidad y de ofrecer un elemento común para el diálogo Sur-Sur en relación a las otras sabidurías ancestrales del Sur Político (Acosta, 2016, p. 31). Es elemento cualificante de la "memoria larga" que sustenta la lucha política y alimenta la utopía en realimentación dialéctica (Cabezas Fernández, 2005; Prada Alcoreza, 2008). En buena parte, por provenir de los pueblos más duramente sometidos y, también, de la reflexión comunitaria realizada en cientos de años de opresión y de lucha contra ella, esta sabiduría ancestral constantemente actualizada contiene un carácter revolucionario.

7) La visión comunitaria en la construcción del conocimiento. La "Forma Comunidad" que marca lo económico, lo político y lo social, marca también lo epistémico como respuesta compartida a los desafíos de una vida compartida.

8) La revisión de la matriz espacio-temporal en la que se gesta este conocimiento y que es determinante en su construcción. Aunque la expresión de la misma es diversa, me animaría a describir a la concepción espacio-temporal presente en las cosmovisiones originarias como en "espiral". Una visión fuertemente dinámica pero no apresurada, no desesperada por avanzar, como aparece predominante en la actualidad occidental. Por esto mismo esta dinámica da la posibilidad de "volver atrás": temporalmente, hacia lo ancestral y espacialmente, hacia las bases comunitarias cuando hay que tomar decisiones que proyecten los caminos a seguir. Esto, tanto en los "altos" niveles políticos como en la cotidianeidad. Este tipo de dinamismo es clave para la motorización, la movilización de la lucha porque tiene la connotación de que la praxis contiene un proceso de reflexión, comprensión, diálogo, deliberación, decisión y planificación comunitarias. En este tipo de dinamicidad espacio-temporal la memoria adquiere un fuerte contenido político. Es la memoria histórica como fuerza interna que permite reconocer las propias capacidades y desarrollar planteos propios (Naveda Félix, 2007, p. 317). En ella está la base para una crítica rotunda a la visión moderno occidental unilineal y teleológica que consagra al "progreso" como horizonte dinámico, sobre todo en las visiones derechistas procapitalistas, pero también en varias versiones de la izquierda eurocéntrica. 


\section{Consideraciones finales.}

El Buen Vivir representa, posiblemente, la propuesta más original y con mayor potencialidad revolucionaria como horizonte de superación del capitalismo, como organización político-económica y como propuesta civilizatoria. Su inmenso valor tiene que ver con su origen popular y su profunda latinoamerinicidad. Ofrecida desde los movimientos indígenas como propuesta político-epistémica estimula la posibilidad de un riquísimo diálogo de saberes emancipatorios y desde allí puede aportar mucho para todas las otras vertientes latinoamericanas que también luchan por una superación del capitalismo. Una muy importante entre ellas es el marxismo. También es una invitación a la confluencia de los movimientos populares contando con la riqueza inmensa del aporte indígena como su componente nuclear.

Es cierto que los planteos políticos concretos que lo invocan $-\mathrm{y}$, sobre todo, las políticas de gobiernotienen, y seguramente van a seguir teniendo, dimensiones ambiguas y muchas veces contradictorias. El trabajo crítico es fundamental para la reflexión y el debate que ayude a coherentizar y concretar esta propuesta en beneficio de las mayorías populares. Pero jamás debe correr el riesgo de terminar coincidiendo con la crítica de la derecha neoliberal, ni inviabilizándola en nombre de alguna forma de purismo que no puede existir en la realidad.

Esto vale, sobre todo, para pensar ese camino transicional que nos lleva a la concreción de ese horizonte en América Latina. Camino bien complejo como todas las concreciones de propuestas revolucionarias pero que hay que recorrer con creatividad heroica al decir de Mariátegui.

Por supuesto que no sirve una idealización del Buen Vivir. Es una propuesta que siempre va a cargar esas ambigüedades y contradicciones mucho más que otras. Justamente porque es una propuesta ancestralmente existente, no viene de una teoría, no viene de un escritorio, viene de siglos de lucha por convivir comunitariamente ligados a la naturaleza y por defender ese tipo de vida. Por eso me animaría a decir que frente al Buen Vivir más que de utopía habría que calificarlo de "subtopía" - aunque no sea muy prolijo juntar el latín y el griego -. Porque tiene un lugar, existe, viene profundamente desde abajo, desde el "abajo social", desde la raíz del continente, desde el subsuelo de América Latina, justamente desde allí sostenía Rodolfo Kusch (1978: 73) que había que "replantear el problema del pensamiento". Esto contribuye también a darle un profundo carácter profundamente subversivo desde lo político y desde lo epistémico. Aquí está su valor, profundizar en ella y encontrar caminos de concretización es el gran desafío.

\section{Notas}

1 Se trata del material del trabajo de campo para mi tesis doctoral realizado en 2009 en Quito, Riobamba, Latacunga, San Antonio de Ibarra y Cotacachi, que está compuesto de 29 entrevistas semiestructuradas, principalmente con dirigentes e integrantes de los Movimientos Indígenas. Fue autorizada la divulgación de las mismas para fines académicos.

2 Pachamama indica en las cosmovisiones andinas el espacio-tiempo vital al cual también pertenecemos los humanos. Suele traducirse al castellano como "naturaleza" o como "tierra", aunque al hacerlo es importante tener en cuenta el sentido originario.

3 Flores Galindo (2008, T. II, p. 464) entiende que, para Mariátegui, el partido no era "exactamente el inicio" de la tarea de la construcción del socialismo "sino casi su estación final" y que "exigía el desarrollo de la 'conciencia de clase'”. Germaná sostiene que Mariátegui defendía "la primacía del movimiento de las organizaciones autónomas de los trabajadores sobre el partido político" ya que "reconocía la iniciativa de los propios trabajadores en la consecución de sus propios objetivos, sin necesidad de un partido político que los dirigiera" ya que "el partido no es la vanguardia del proceso revolucionario, pues este papel lo tienen las organizaciones autónomas de los trabajadores". Cercanamente, Aricó (2017, p. 317), entiende que en la propuesta mariateguiana "El partido político debía crecer, no como un todo completo, sino en sus elementos constitutivos, en el interior del movimiento de masas en desarrollo, y solo en relación con dicho movimiento el partido encontraba su razón de ser, la garantía contra una sectarización que lo llevara a encontrar en sí mismo las razones de su propia existencia”. Flores Galindo (2008, T. II, p. 465) sostiene que Aricó y Germaná al sugerir "que el sindicato en Mariátegui terminó por ser más importante que el partido" exageran, pero que se trata de una exageración "necesaria para mostrar que el partido no era pensado fuera ni tampoco por encima de la clase, sino que se iría formando al interior del movimiento de masas" y que el trabajo de construcción 
de la organización sindical y del partido "se plantean como tareas complementarias y paralelas".

4 Y anticipa el concepto de Fals Borda del "sentipensamiento" al entender que los juicios se nutren de los sentimientos. Fals Borda (2008: 20-21) se reconoce en el camino de Mariátegui y José María Arguedas.

5 La relación entre Mariátegui y el Che merece otro estudio y es muy importante hacerlo por lo que ambos significan en la lucha revolucionaria latinoamericana. Una figura clave aquí fue Hugo Pesce.

\section{REFERÊNCIAS}

ACOSTA, Alberto. (2016), "Aporte al debate: el extractivismo como categoría de saqueo y de devastación". FIAR. Forum for inter-american research. 9, 2: 25-33.

ACOSTA, Alberto. (2010), El Buen Vivir en el camino del post-desarrollo. Una lectura desde la Constitución de Montecristi. Quito, FES-ILDIS.

ACOSTA, Alberto. (2014), "El Buen Vivir, más allá del desarrollo", in G. C. Delgado Ramos (comp.), Buena Vida, Buen Vivir: imaginarios alternativos para el bien común de la humanidad, México, UNAM.

ALTMANN, Philipp. (2016), "Buen Vivir como propuesta política integral: Dimensiones del Sumak Kawsay", Revista Latinoamericana de Políticas y Acción Pública, 3, 1: 55-74.

ARICÓ, José. (2017), Dilemas del marxismo en América Latina. Antología esencial. Buenos Aires, CLACSO.

CABEZAS FERNÁNDEZ, Marta. (2005), "Bolivia: Tiempos rebeldes. Coyuntura y causas profundas de las Movilizaciones Indígena-Populares.", AIBR. Revista de Antropologia Iberoamericana, 41.

CONCHEIRO BÓRQUEZ, Luciano \& NÚNEEZ, Violeta Núńez. (2014), "El 'Buen Vivir' en México: ¿Fundamento para una perspectiva revolucionaria?", in G. C. Delgado Ramos (coord.), o. c.

CRUVINEL, Tereza. (2020), "Homens da CIA no golpe da Bolívia", Brasil247, 22 de febrero, https://www.brasil247.com/blog/homens-dacia-no-golpe-da-bolivia
CHAMORRO, Graciela. (2004), "La Buena Palabra. Experiencias y reflexiones religiosas de los grupos Guaraníes", Revista de Indias, LXIV, 230: 117-140.

CHURUCHUMBI, Guillermo. (2014), Usos cotidianos del término Sumak Kawsay en el territorio Kayambi. Cayambe, Universidad Andina Simón Bolívar / Ecuador.

DUSSEL, Enrique. (1987), Ética comunitaria. Florida (Bs.As.), Paulinas.

DUSSEL, Enrique. (1977), Introducción a la Filosofía de la Liberación. México, Extemporáneos.

ESCÁRZAGA NICTÉ, Fabiola. (2017), "Las comunidades interculturales y la política agraria del gobierno de Evo Morales", in J. C. Gómez Leyton (ed.), Bolivia hoy: ¿Democracia Poscolonial o Anticolonial?, Santiago de Chile, Escaparate.

FALS BORDA, Orlando. (2008), El socialismo raizal y la Gran Colombia bolivariana. Investigación Acción Participativa. Caracas, El perro y la rana.

FLORES GALINDO, Alberto. (2008), Obras completas. Lima, Sur.

GARCÍA LINERA, Álvaro. (2001), "Multitud y comunidad. La insurgencia social en Bolivia.", Revista Chiapas, UNAM, 11.

GARCÍA LINERA, Álvaro. (2017), "La globalización ha muerto", Educere, 21, 68: 183-186.

GERMANÁ, César. (1995), El "socialismo indoamericano" de José Carlos Mariátegui: proyecto de reconstitución del sentido histórico de la sociedad peruana. Lima, Amauta.

GUDYNAS, Eduardo. (2011), "Buen Vivir: germinando alternativas al desarrollo", Alainet, 462.

GUDYNAS, Eduardo. (2010), "Buen Vivir: un necesario relanzamiento", Yachaykuna, 13: 40-46.

GUDYNAS, Eduardo. (2017), "Los ambientalismos frente a los extractivismos", Nueva Sociedad, 268: 110-121.

KUSCH, Rodolfo. (1978), Esbozo de una Antropología Filosófica Americana. Buenos Aires, Castañeda.

LALANDER, Rickard \& OSPINA PERALTA, Pablo. (2012), "Movimiento Indígena y Revolución Ciudadana en Ecuador", Cuestiones políticas, 28, 48: $13-50$. 
LÖWY, Michael. (2008), "Ni calco, ni copia: el marxismo romántico de José Carlos Mariátegui", 7 Ensayos, 80 años, I, 2: 1-5.

MACAS, Luis. (2010), "El Sumak Kawsay", Yachaykuna, 13: 13-39.

MACAS, Luis. (2005), "La necesidad política de una reconstrucción epistémica de los saberes ancestrales”, in P. Dávalos (coord.), Pueblos indigenas, estado y democracia. Buenos Aires, CLACSO.

MAMANI CONDORÍ, Carlos. (2007), "Memoria y reconstitución", in C. Zapata Silva (ed.), Intelectuales indigenas piensan América Latina, Quito, Abya Yala.

MARIÁTEGUI, José Carlos. (2000), 7 ensayos de interpretación de la realidad peruana. Caracas, Fundación Biblioteca Ayacucho.

MARIÁTEGUI, José Carlos. (2005), Invitación a la vida heroica. Lima, Fondo Editorial del Congreso del Perú.

MARIÁTEGUI, José Carlos. (2010a), El alma matinal y otras estaciones del hombre de hoy y el artista y la época. Caracas, El perro y la rana.

MARIÁTEGUI, José Carlos (2010b), Ideología y política y otros escritos. Caracas, El perro y la rana.

MARIÁTEGUI, José Carlos. (2017), Defensa del marxismo y otros escritos. Caracas, El perro y la rana.

MARX, Karl. (1990), "Karl Marx: Carta al Consejo Editorial de Otechestvennye Zapiski”, in T. Shanin (edit.), El Marx tardio y la vía rusa. Marx y la periferia del capitalismo. Madrid, Revolución.

MAZZEO, Miguel. (2009), Invitación al descubrimiento. José Carlos Mariátegui y el socialismo de Nuestra América. Buenos Aires, El Colectivo.

NAVEDA FÉLIX, Igidio. (2007), "Reconstitución de pueblos indígenas en la región andina y el rol de los intelectuales indígenas", in C. Zapata Silva (comp.), o. c.

PAOLI, Antonio. (2001), "Lekil kuxlejal. Aproximaciones al ideal de vida entre los tseltales", Revista Chiapas, UNAM, 12.

PRADA ALCOREZA, Raúl. (2008), Subversiones indígenas, La Paz, CLACSO / Muela del Diablo / Comuna.
QUIJANO, Aníbal. (2014), Cuestiones y horizontes: de la dependencia histórico-estructural a la colonialidad / descolonialidad del poder. Buenos Aires, CLACSO.

SANTOS, Boaventura de Souza. (2010), "'Hablamos del Socialismo del Buen Vivir”, Alainet, 452: 4-7.

STAVENHAGEN, Rodolfo. (1970), "Marginalidad, participación y estructura agraria en América Latina”, Demografía y Economía, IV, 3: 267-291.

TENESACA CAGUANA, José Delfín. (2013), Proceso organizativo de la Ecuarunari: un análisis desde las Asambleas Plurinacionales 2009-2011. Quito, Universidad Politécnica Salesiana.

TORTOSA, José María. (2011), Maldesarrollo y mal vivir. Pobreza y violencia a escala mundial. Quito, Abya Yala.

YAMPARA HUARACHI, Simón. (2007), “¿Cambio estructural del sistema educativo o remozamiento de lo mismo?", in J. L. Saavedra (comp.), Educación superior, interculturalidad y descolonización, La Paz, PIEB-CEUB.

\section{ENTREVISTAS}

CHELA, Bélgica. Entrevista. Félix Pablo Friggeri. 23, enero 2009. Sede de Escuelas Radiofónicas Populares del Ecuador (ERPE), Riobamba.

CHOLANGO, Humberto. Entrevista. Félix Pablo Friggeri. 30, enero 2009. Sede de la Confederación de los Pueblos de la Nacionalidad Kichwa del Ecuador - ECUARUNARI, Quito.

PUCHA, Julián. Entrevista. Félix Pablo Friggeri. 24, enero 2009. Sede de la Confederación del Movimiento Indígena del Chimborazo (COMICH), Riobamba.

SARANGO MACAS, Luis Fernando. Entrevista. Félix Pablo Friggeri. 18, enero 2009. Sede de la Universidad Intercultural Amawtay Wasi, Quito.

VARGAS, Fausto. Entrevista. Félix Pablo Friggeri. 20, enero 2009. Sede de la Confederación Nacional de Pueblos y Nacionalidades Indígenas del Ecuador (CONAIE), Quito. 


\section{BUEN VIVIR Y \\ SOCIALISMO \\ INDOAMERICANO: \\ UNA BÚSQUEDA \\ EPISTÉMICO-POLÍTICA}

Félix Pablo Friggeri

Palabras-clave: Buen Vivir; Socialismo Indoamericano; Mariátegui; Movimientos Indígenas; América Latina.

Presento aquí el planteo indígena del Buen Vivir y su relación con el Socialismo Indoamericano -en la línea de Mariátegui- en la búsqueda de un horizonte de superación del capitalismo y de sus presupuestos, trabajando sobre la doble dimensión política y epistémica de estas propuestas. Analizo las expresiones indígenas del Buen Vivir y sus elementos comunes: El dilema de su relación con el desarrollo, la relación con otros planteos latinoamericanos en esta línea, específicamente con la propuesta de Mariátegui, y el valor del planteo epistémico por su originalidad y potencialidad revolucionaria. Pretendo contribuir a la reflexión sobre la relación entre las propuestas latinoamericanas que se proponen un camino de superación del capitalismo en nuestra región. Trabajo con material de entrevistas realizadas junto a los movimientos indígenas ecuatorianos en diálogo con material bibliográfico.

\section{BEM VIVER E \\ SOCIALISMO \\ INDOAMERICANO: UMA BUSCA EPISTÊMICO- POLÍTICA}

\section{Félix Pablo Friggeri}

Palavras-chave: Bem Viver; Socialismo indo-americano; Mariátegui; Movimentos indígenas; América Latina.

Apresento aqui a abordagem indígena do Bem Viver e sua relaçáo com o socialismo indo-americano - na linha de Mariátegui-, em busca de um horizonte para a superação do capitalismo e de seus pressupostos, trabalhando na dupla dimensão política e epistêmica dessas propostas. Analiso as expressóes indígenas do Bem Viver e seus elementos comuns: o dilema de sua relaçáo com o desenvolvimento; o relacionamento com outras abordagens latino-americanas nessa linha, especificamente com a proposta de Mariátegui, e o valor da abordagem epistêmica por sua originalidade e potencial revolucionário. Pretendo contribuir para a reflexão sobre a relaçáo entre as propostas latinoamericanas que propóem uma maneira de superar o capitalismo em nossa região. Trabalho com material de entrevistas realizadas com movimentos indígenas equatorianos em diálogo com material bibliográfico.

\section{GOOD LIVING AND INDOAMERICAN \\ SOCIALISM: AN EPISTEMIC-POLITICAL SEARCH}

Félix Pablo Friggeri

Keywords: Good Living; IndoAmerican Socialism; Mariátegui; Indigenous Movements; Latin America.

I present here the indigenous approach to Good Living and its relationship with IndoAmerican Socialism -in the line of Mariátegui- in search of a horizon for overcoming capitalism and its budgets, working on the double political and epistemic dimension of these proposals. I analyze the indigenous expressions of Good Living and their common elements; the dilemma of its relation to development; the relationship with other Latin American approaches in this line, specifically with Mariátegui's proposal, and the value of the epistemic approach for its originality and revolutionary potential. I intend to contribute to the reflection on the relationship between the Latin American proposals that propose a way to overcome capitalism in our region. I work with material from interviews carried out with the Ecuadorian indigenous movements in dialogue with bibliographic material.

\section{BIEN-VIVRE ET SOCIALISME INDO- AMÉRICAIN, UNE QUÊTE ÉPISTÉMICO- POLITIQUE}

Félix Pablo Friggeri

Mots-clés: Bien-vivre; socialisme indo-américain; Mariátegui; mouvements indigènes; Amérique latine.

Ce travail propose une approche indigène du bien-vivre et sa relation avec le socialisme indoaméricain - dans la lignée de Mariátegui - pour tenter d'aller au-delà du capitalisme et de ses présupposés, en mettant l'accent sur les dimensions politique et épistémique des propositions. Sont ainsi analysées les expressions indigènes du bien-vivre et leurs éléments communs; le dilemme concernant son rapport au développement ; la relation avec d'autres approches latinoaméricaines, en particulier celle de Mariátegui ; et la valeur de l'approche épistémique en matière d'originalité et de potentiel révolutionnaire. L'objectif est de contribuer à la réflexion sur le lien entre les propositions latino-américaines qui mettent en avant la possibilité de surmonter le capitalisme dans cette région. Pour ce faire, l'analyse se base sur des entretiens de mouvements indigènes équatoriens en dialogue avec le matériel bibliographique. 